\title{
CAMPANHAS AUDIOVISUAIS DE PREVENÇÃO EM SEGURANÇA E SAÚDE NO TRABALHO E O PERFIL DE AGRAVOS NO BRASIL
}

\author{
AUDIOVISUAL OCCUPATIONAL SAFETY AND HEALTH PREVENTION \\ CAMPAIGNS AND THE PROFILE OF INJURIES IN BRAZIL
}

\author{
CAMPAÑAS DE PREVENCIÓN AUDIOVISUAL SOBRE SALUD Y \\ SEGURIDAD EN EL TRABAJO Y EL PERFIL DE LAS LESIONES EN BRASIL
}

Leo Vinicius Maia Liberato

(FUNDACENTRO, Brasil)

\section{https://doi.org/10.29404/rtps-v5i8.355}

\begin{abstract}
RESUMO: buscou-se nessa pesquisa trazer conhecimento sobre quais setores e atividades econômicas estão prevalecendo ou sendo preteridos em campanhas preventivas públicas em Segurança e Saúde no Trabalho. Haveria alguma discrepância entre os dados públicos oficiais sobre acidentes e doenças do trabalho no Brasil e o enfoque das campanhas preventivas? A pesquisa aqui apresentada também visou identificar os atores a quem as mensagens preventivas eram dirigidas, assim como os atores responsabilizados pela prevenção nas mensagens. Para tanto, um corpus contendo setenta vídeos de campanhas preventivas foi construído para análise de conteúdo. Entre os resultados obtidos, destaca-se a escassa abordagem do setor de transportes apesar da sua alta taxa de mortalidade e de mortes em números absolutos. Recomenda-se que campanhas preventivas abordem atividades desse setor, a de professores, trabalhadores informais, trabalhadores de limpeza e vigilância, e que se dirijam a outros atores além do trabalhador.
\end{abstract}

Palavras-chave: segurança e saúde no trabalho, prevenção, políticas públicas.

ABSTRACT: this research have sought to add knowledge about which sectors and economic activities are prevailing or being neglected in public preventive campaigns in Safety and Health at Work. Would there be any discrepancy between the official public data on accidents and occupational diseases in Brazil and the focus of preventive campaigns? In addition to answering this question, the research presented here aimed to identify the actors to whom the preventive messages were addressed, as well as the actors responsible for preventive action in the messages. To this end, a corpus containing seventy videos of preventive campaigns was built for content analysis. Among the results obtained, the scarce approach of the transport sector, despite the high rates of mortality and deaths in absolute numbers. It is recommended that preventive campaigns address activities in that sector, and that of teachers, informal workers, cleaning, and surveillance workers, and also that they address other actors besides the worker.

Keywords: occupational safety and health; prevention; public policies
RESUMEN: esta investigación buscó aportar conocimiento sobre qué sectores y actividades económicas prevalecen 0 se descuidan en las campañas preventivas públicas en Seguridad y Salud en el Trabajo. ¿Habría alguna discrepancia entre los datos públicos oficiales sobre accidentes y enfermedades profesionales en Brasil y el enfoque de las campañas preventivas? Además de responder a esta pregunta, la investigación presentada aquí tenía como objetivo identificar a los actores a quienes se dirigían los mensajes preventivos, así como a los actores responsables de la prevención en los mensajes. Con este fin, se creó un corpus que contenía setenta videos de campañas preventivas para el análisis de contenido. Entre los resultados obtenidos, destaca el escaso enfoque del sector del transporte a pesar de su alta tasa de mortalidad y muertes en números absolutos. Se recomienda que las campañas preventivas aborden actividades en este sector, el de maestros, trabajadores informales, trabajadores de limpieza y vigilancia, y que se dirijan a otros actores además del trabajador.

Palabras claves: seguridad y salud ocupacional; prevención; políticas públicas 


\section{Introdução}

Notoriamente, as bases de dados de acidentes e doenças de trabalho no Brasil estão dispersas em diferentes órgãos (INSS, Ministério do Trabalho/Economia, Ministério da Saúde e IBGE, por exemplo). Além disso, o fato de grande parte dos dados se restringirem ao trabalho formalizado e a provável elevada subnotificação de acidentes e doenças do trabalho, entre outros fatores, tornam os números, em geral, muito pouco precisos. Apesar disso, eles podem ser úteis para termos alguma orientação sobre o quadro geral de acidentes e doenças do trabalho no Brasil em relação a características setoriais e atividades, pelo menos quanto aos trabalhadores formalizados.

Segundo o Pnad do IBGE, em 2016 o país possuía 139 milhões de pessoas ocupadas ou que foram recentemente ocupadas. Segundo a RAIS do Ministério do Trabalho, em 2016 havia cerca de 46 milhões de empregados formais. As taxas de mortalidade mais altas, segundo dados de 2014 da Previdência e do Ministério do Trabalho, são encontradas na extração mineral, construção civil e setor primário, mas é no setor terciário que são encontrados o maior número absoluto de afastamentos por acidentes e doenças ocupacionais (DIEESE, 2016). Dados esses coerentes com a terciarização da economia, isto é, o aumento do número de empregados no setor de serviços concomitante a uma redução relativa dos setores primário e secundário. Segundo o Pnad do IBGE de 2016, 67,7\% da população ocupada trabalhava no setor terciário, $14,2 \%$ na indústria, $10,4 \%$ no setor primário e 7,7\% na construção civil. Segundo dados do Ministério do Trabalho, em 2016, $36,3 \%$ dos empregos formais estavam no setor de Serviços, 20,1\% no Comércio e 19,2\% na Administração Pública.

De acordo com a Pesquisa Nacional de Saúde realizada pelo IBGE em 2013, naquele ano 1,627 milhão de pessoas maiores de dezoito anos deixaram de realizar suas atividades por conta de acidentes típicos de trabalho, de um total de 3,2 milhões que sofreram esses acidentes. Segundo os dados da Relação Anual de Informações Sociais (RAIS), do Ministério do Trabalho, a taxa de mortalidade por agravos relacionados ao trabalho em 2014 foi de 3,8 para cada 100 mil vínculos empregatícios. Sendo que 2,8 por acidentes típicos, 0,8 por acidentes de trajeto e 0,2 por doenças ocupacionais (DIEESE, 2016).

O setor de serviços (terciário) no Brasil já soma $67 \%$ das ocupações ou $75 \%$ dos empregos formais, dependendo da fonte que usarmos. Embora dentro de "serviços" tenhamos atividades tão distintas quanto motoristas de caminhão, professores, faxineiros, vendedores, vigilantes, empregados domésticos, mecânicos de manutenção etc., há uma expectativa de que à medida que os serviços ganham volume sobre a indústria e agricultura, os agravos relacionados ao trabalho migrem, em parte, das lesões por acidentes típicos para as doenças ocupacionais. No entanto, dos afastamentos previdenciários reconhecidos como relacionados ao trabalho cerca de $2 / 3$ são consequência de acidentes e 1/3 de doenças. Mesmo no setor de serviços o afastamento por acidentes é bastante superior aos afastamentos por doenças ocupacionais (DIEESE, 2016). Certamente para isso contribui a invisibilidade ou ocultação (FILGUEIRAS, 2017a), 
que recai principalmente sobre as doenças ocupacionais e setores onde os sindicatos são mais fracos, como, por exemplo, os de serviços de limpeza e restaurantes.

Em relação aos acidentes de trabalho típicos, as atividades de transporte rodoviário, principalmente motorista de caminhão e motofretista, se destacam em números absolutos de mortes, de aposentadorias por invalidez decorrentes de acidente de trabalho e em taxa de mortalidade (DIEESE, 2016). Isso reflete, por exemplo, o modal de transporte que foi privilegiado historicamente pelas políticas públicas no Brasil e possivelmente também uma mudança na estrutura produtiva, com maior importância da circulação e transporte para suprir a ausência de estoques (just-in-time) e conectar um processo de produção em unidades descentralizadas ou dispersas. A construção civil, a extração mineral e o setor primário também apresentam elevado risco de morte no trabalho, visto possuírem altas taxas de mortalidade por acidente. Juntamente com a indústria, são responsáveis também pela maior parte e maior taxa de acidentes graves (DIEESE 2016). E lembremos que taxas de lesões leves são mais afetadas pela dificuldade de afastamento do trabalho, por isso, como Nichols (1999) expôs claramente, as taxas de lesões graves são indicadores melhores sobre a segurança no trabalho.

Motocicletas e veículos de transporte entre os maiores "agentes" de acidentes de trabalho nos mostra mais uma vez o destaque negativo das atividades de transporte rodoviário na acidentalidade no trabalho. A alta presença de máquinas, equipamentos, ferramentas, agentes químicos e biológicos nos fazem lembrar também da importância nos números de acidentes da indústria e de algumas atividades de serviço, como atendimento hospitalar. Acidentes em profissões da saúde são proeminentes em alguns bancos de dados. Temos como hipótese que isso se deve também a uma menor subnotificação dos acidentes comparativa nesse setor.

O setor terciário responde por cerca de $80 \%$ do total das aposentadorias por invalidez permanente decorrentes de doença ocupacional (MINISTÉRIO DO TRABALHO, 2017). Fração um pouco superior a de empregos formais no setor em relação à totalidade de empregos formais. Mas quanto à taxa de aposentadorias por invalidez permanente devido à doença ocupacional, se destacam os Serviços Industriais de Utilidade Pública, o serviço público e o setor primário (DIEESE, 2016). Podemos tomar a aposentadoria permanente por invalidez como um índice da severidade da doença.

Servidores públicos tem se destacado nos números absolutos de afastamentos por doença ocupacional. Dentre eles, os professores do ensino fundamental e de jovens e adultos tem sido uma categoria particularmente afetada (DIEESE, 2016). Nos afastamentos por doença ocupacional aparecem também com incidência elevada trabalhadores em hospitais, da construção civil, industriais, bancários, motoristas de ônibus, vigilantes e comércio (supermercados).

Quanto às doenças ocupacionais que se destacam nos dados de afastamentos estão, por ordem decrescente: dor nas costas, lesões no ombro, patologias mentais, Lesões por Esforços Repetitivos (LER) e os Distúrbios Osteomusculares Relacionados ao Trabalho 
(DORT). As patologias mentais estão em tendência de crescimento, ao menos relativo às demais doenças que tem gerado afastamentos.

A partir desse perfil de acidentes e doenças ocupacionais no Brasil, a questão que esse artigo busca ajudar a responder, através de uma pesquisa realizada com vídeos públicos de campanhas de prevenção de acidentes e doenças de trabalho, é quais setores econômicos e atividades tem prevalecido nas campanhas preventivas públicas de Segurança e Saúde no Trabalho (SST). Portanto, o objetivo foi aferir a existência de discrepâncias entre os dados oficiais sobre acidentes, adoecimentos e mortes decorrentes do trabalho e o enfoque das campanhas preventivas. Além disso, apresentamos os atores sociais cujas mensagens preventivas são dirigidas e quais atores tem predominado como responsáveis pela prevenção nas mensagens. Dessa forma possibilita-se enxergar criticamente essas campanhas, com base no conhecimento estabelecido sobre a importância dos diversos atores sociais na prevenção: trabalhadores na operação, gestores públicos e privados etc. (ALMEIDA, 2006; MENÉNDEZ-NAVARRO, 2019).

Os resultados aqui apresentados são parte dos resultados de uma pesquisa mais ampla que teve como objetivo agregar conhecimento de quais fatores de risco, setores, atividades e paradigmas prevalecem em campanhas preventivas de Segurança e Saúde no Trabalho produzidas no Brasil, e quais lacunas estão sendo deixadas tendo em vista os agravos mais frequentes, sua gravidade e mudanças contemporâneas no mundo do trabalho.

\section{Metodologia}

Com base em investigação exploratória buscando vídeos online de campanhas preventivas em SST, decidimos construir o corpus para análise com vídeos disponibilizados publicamente numa mesma plataforma, o Youtube. A escolha se deu por se tratar de uma plataforma de amplo conhecimento e acesso público, e porque os vídeos de campanhas preventivas de SST disponíveis nessa plataforma já eram mais do que suficientes para a construção do corpus.

Selecionamos vídeos produzidos por entidades estatais, patronais e sindicais (dos trabalhadores). Para entidades do Estado, incluímos vídeos de campanhas produzidos e disponibilizados no Youtube pelo Ministério do Trabalho, Ministério Público do Trabalho e Tribunal Superior do Trabalho. Por parte do empresariado selecionamos vídeos de campanhas do chamado Sistema $\mathrm{S}$, embora não tenhamos encontrado campanhas preventivas através de vídeos de todas as entidades desse sistema. Buscamos vídeos das seguintes entidades: Serviço Social da Indústria (SESI), Serviço Social do Comércio (SESC) e FECOMÉRCIO/CNC/SENAC; Serviço Nacional de Aprendizagem Rural (SENAR) e Confederação da Agricultura e Pecuária do Brasil (CNA); Serviço Brasileiro de Apoio às Micro e Pequenas Empresas (SEBRAE); e Serviço Social do Transporte (SEST) e Confederação Nacional dos Transportes/Serviço Nacional de Aprendizagem dos Transportes (CNT/SENAT). No levantamento para construção do corpus nos deparamos 
com vídeos da Câmara Brasileira da Indústria da Construção, que também selecionamos como representativos das entidades patronais. Do mesmo modo selecionamos também alguns vídeos da Vale, segunda maior empresa do país, pois possuíam vídeos bem produzidos de campanhas preventivas.

O período de coleta foi o mês de julho de 2018, compreendendo vídeos que fossem produzidos/disponibilizados entre 2006 e a data da coleta. As palavras ou expressões utilizadas para a busca e seleção dos vídeos na plataforma Youtube foram: "prevenção", "acidente", "doença", "saúde", "assédio moral", "riscos psicossociais", "condições de trabalho" e "ambiente de trabalho". Posteriormente verificamos se os vídeos tratavam de assunto referente à prevenção em SST, excluindo os que fossem reportagens de eventos sobre o tema e os que tratassem de ações reparatórias e de reinserção no trabalho. Outros vídeos que apareceram em outras buscas ou que vieram a nosso conhecimento ao acaso também foram levados em consideração para formação do corpus.

É preciso ressaltar que a busca realizada com as palavras ou expressões mencionadas acima tendem a levar a vídeos com concepções preventivas próprias de um campo bem delimitado e estabelecido de SST. Abordagens que não separam o processo produtivo, a organização do trabalho e a saúde são mais difíceis de serem detectadas por uma busca com esses termos. Esse é um entre outros prováveis motivos para as entidades dos trabalhadores aparecerem com número menor de vídeos de campanhas de SST na nossa busca. Se pensarmos no movimento operário italiano nos anos 1970, a prevenção em SST não era algo separado e nem tão visível como um tema em si. Ela era em grande parte inseparável da luta contínua pelo controle do processo produtivo (LIBERATO, 2014). O fato é que as centrais sindicais parecem não produzir vídeos com temática relacionada a condições de trabalho e saúde do trabalhador. A produção dos vídeos de campanhas sobre esses temas que encontramos e que selecionamos para o corpus está dispersa entre os inúmeros sindicatos locais e por profissões, que caracterizam o nosso sindicalismo oficial.

Cabe destacar também que foram preteridos vídeos de campanhas preventivas cujo conteúdo focava em estatística de acidentes e adoecimentos ou na descrição da atividade de algum órgão estatal. Também não foram selecionados vídeos de programas de instrução de procedimentos e videoaulas de SST.

Compuseram o corpus 33 vídeos de entidades estatais, 11 vídeos de entidades sindicais dos trabalhadores e 26 vídeos de entidades patronais, totalizando 70 vídeos.

Utilizamos como principal referência metodológica para a análise de conteúdo de um corpus de vídeos, Aarts e Bauer (2008). Os objetos de interpretação nos vídeos foram: forma narrativa; contexto; ambiente; linguagem não verbal; linguagem verbal. A partir desses objetos de interpretação, identificamos, com a frequência em que aparecem: a) os atores a quem a mensagem é dirigida; b) a responsabilidade atribuída a atores por acidentes ou pela prevenção; c) os setores/atividades abordados.

Quando o vídeo é composto por diferentes contextos, situações e histórias, a contagem de frequência marca o número de contextos, situações ou histórias em que a 
categoria de análise esteve presente. Portanto, a frequência não corresponde necessariamente ao número de vídeos em que tal categoria apareceu.

\section{Resultados e discussão}

Podemos ver pela Tabela 1 que os trabalhadores são nitidamente os atores mais visados nas mensagens preventivas nos vídeos públicos selecionados que compuseram o corpus. Mesmo excluindo os vídeos das entidades sindicais - que visam os trabalhadores porém em geral sem responsabilizá-los, como é mais frequente nos vídeos de entidades estatais e principalmente patronais - é substancialmente maior a frequência dos trabalhadores como alvo da mensagem, chegando a ser seis vezes maior que em relação aos empregadores ou gestores. Comparando as Tabelas 1 e 2 percebemos como que, no caso das entidades sindicais, há uma desproporção acentuada das frequências dos trabalhadores como alvo da mensagem e da atribuição da responsabilidade preventiva a eles. No caso das entidades estatais e patronais esses números são mais proporcionais. $O$ que leva a crer que as entidades sindicais visam os trabalhadores nos seus vídeos, mas não colocam sobre eles a responsabilidade preventiva, ao contrário do que em geral fazem as entidades estatais e patronais quando se dirigem aos trabalhadores.

A concentração da frequência dos trabalhadores como alvo da mensagem é maior nos vídeos das entidades patronais do que nos das estatais. Por sua vez, as entidades estatais se dirigem menos especificamente aos empregadores do que as entidades patronais.

Tabela 1 - Frequências dos atores alvo das mensagens dos vídeos

\begin{tabular}{lccc}
\hline \multirow{2}{*}{ Vídeos } & \multicolumn{3}{c}{ Atores-alvo } \\
\cline { 2 - 4 } & Trabalhadores & Empregadores/Gestores & Público em geral \\
\hline Estatais & 22 & 1 & 25 \\
\hline Sindicais & 11 & 0 & 2 \\
\hline Patronais & 28 & 7 & 6 \\
\hline Total & 61 & 8 & 33 \\
\hline Fonte: elaboração própria & & &
\end{tabular}

No corpus analisado, a partir da Tabela 2 podemos perceber que globalmente os trabalhadores são mais responsabilizados pela prevenção, seguidos pelos empregadores ou gestores; com outros atores aparecendo de forma pouco significativa se comparados a esses dois. Nos vídeos produzidos por sindicatos de trabalhadores podemos perceber que a própria atribuição de responsabilidade a algum ator aparece muito pouco, e quase metade das vezes em que aparece essa responsabilidade é atribuída aos empregadores. Já 
nos vídeos das entidades estatais e patronais foi possível perceber com bastante frequência uma atribuição de responsabilidade preventiva. Se nos vídeos das entidades estatais a responsabilidade aparece proporcionalmente dividida entre trabalhadores $\mathrm{e}$ empregadores, já nos das entidades patronais a responsabilidade dos trabalhadores aparece com frequência mais de três vezes maior que a de empregadores.

O foco no trabalhador e na sua responsabilização pela segurança e saúde no trabalho caracterizam o que Filgueiras (2007b) e Menéndez-Navarro (2019) apontam como uma individualização da responsabilidade preventiva, que seria antinômica ao foco preventivo nas questões de ambiente e organização do trabalho. Para Filgueiras (2007b) a individualização é um aspecto fundamental da gestão de SST no Brasil. Ao lado da ocultação de acidentes e adoecimentos e da confrontação às regras e conhecimentos de SST, a individualização seria uma estratégia de manutenção de uma gestão predatória da força de trabalho (Filgueiras 2007b). Nesse sentido, as frequências apresentadas nas Tabelas 1 e, principalmente, na Tabela 2, confirmam essa tendência de individualização e apontam que ela ocorre principalmente por parte dos empregadores/gestores. Embora, como salienta Filgueiras (2007b), a individualização em segurança e saúde no trabalho é tão disseminada que chega a ser incorporada pelos próprios trabalhadores, ganhando ares de senso comum.

\section{Tabela 2 - Frequências de atores com responsabilidade preventiva atribuída nas} mensagens dos vídeos.

\begin{tabular}{cccccc}
\hline & \multicolumn{5}{c}{ Responsabilidade Preventiva } \\
\cline { 2 - 6 } Vídeos & Trabalhadores & $\begin{array}{c}\text { Empregadores } \\
\text { /gestores }\end{array}$ & $\begin{array}{c}\text { Sociedade em } \\
\text { geral }\end{array}$ & Estado & Sindicato \\
\hline Estatais & 24 & 24 & 3 & 3 & 0 \\
Sindicais & 1 & 3 & 0 & 1 & 1 \\
Patronais & 37 & 13 & 0 & 0 & 0 \\
Total & 62 & 40 & 3 & 4 & 1 \\
\hline Fonte: elaboração própria & & & &
\end{tabular}

A Tabela 3 mostra as frequências de setores de atividade econômica abordados nos vídeos do corpus analisado. A Construção civil se destaca, e embora não tenha sido uma amostragem estatística, na seleção do corpus tivemos a percepção de que é o setor que tem sido alvo de mais campanhas preventivas públicas em vídeo. Por outro lado, entre as entidades sindicais, encontra-se mais facilmente vídeos que se relacionam ao setor terciário. $O$ baixo número de vídeos de campanhas preventivas voltadas ao setor rural que percebemos, talvez se explique pelo vídeo não ser o meio mais apropriado para chegar aos atores desse setor, principalmente se se tem em mente o trabalhador como alvo. O setor de transporte, apesar da alta mortalidade e acidentalidade, também tem tido relativamente poucos vídeos de campanhas preventivas, pelo que percebemos ao selecionar o corpus. 
Talvez isso se explique pelo transporte ser visto como uma questão para além das relações de trabalho, já que grande parte da atividade se dá normalmente também em vias públicas e os acidentes também ocorrem em grande número com não-trabalhadores durante seus deslocamentos.

\section{Tabela 3 - Frequências de setor/atividade econômica nas mensagens dos vídeos.}

\begin{tabular}{lccccccc}
\hline & \multicolumn{7}{c}{ Setor } \\
\cline { 2 - 8 } Vídeos & Indústria & Rural & Serviços & $\begin{array}{c}\text { Construção } \\
\text { Civil }\end{array}$ & Transporte & $\begin{array}{c}\text { Cozinha } \\
\text { industrial e } \\
\text { Panificadora }\end{array}$ & Mineração \\
\hline Estatais & 9 & 3 & 8 & 17 & 2 & 2 & 0 \\
Sindicais & 2 & 0 & 7 & 0 & 0 & 0 & 0 \\
Patronais & 6 & 1 & 2 & 5 & 6 & 0 & 3 \\
Total & 17 & 4 & 17 & 22 & 8 & 2 & 3 \\
\hline Fonte: elaboração própria & & & & & & &
\end{tabular}

De um modo geral, para avaliarmos se os vídeos de campanhas preventivas em SST estariam abordando numa idealizada "proporção devida" os agravos, atividades, setores, fatores de risco ou perigos, teríamos que ter uma equação que levasse em conta quantidade, gravidade e taxa de ocorrência dos agravos globalmente e nos setores e atividades. De todo modo, levando em conta o que apresentamos sobre o perfil de acidentalidade e adoecimento do trabalho no Brasil, e os resultados das frequências das diversas categorias extraídas do corpus de vídeos utilizado, assim como com o que apreendemos no próprio processo de seleção de vídeos e de construção do corpus, podemos chegar a algumas conclusões. Essas conclusões dizem respeito a lacunas ou baixa representação nos vídeos de campanhas preventivas de setores, profissões ou atividades com altas taxas ou índices de acidentes, mortes ou adoecimentos relacionados ao trabalho.

As atividades do setor de transporte - motofretista, motorista de caminhão, entre outras - destacam o setor negativamente, com o maior número absoluto de mortes, com a maior taxa de mortalidade e de aposentadorias por invalidez decorrentes de acidente de trabalho. Ou seja, os transportes, ou mais especificamente os transportes rodoviários, se destacam tanto pela quantidade e pela gravidade de acidentes de trabalho, quanto pela taxa de fatalidade. No entanto esses altos índices não correspondem ao que se poderia esperar em relação às campanhas preventivas em vídeo. Na construção do corpus nos deparamos com relativamente poucos vídeos de prevenção em SST voltados ao setor de transporte, fossem produzidos por entidades estatais, dos trabalhadores ou patronais. Buscamos conceder uma boa representatividade numérica a eles no corpus, por se tratar de um setor com altíssima acidentalidade, por isso selecionamos até mesmo um vídeo, do Ministério dos Transportes, voltado aos acidentes de trânsito em geral, sem especificidade em relação à atividade profissional de motorista ou condutor, por exemplo. Há que se 
levantar hipóteses sobre essa quase ausência de foco de vídeos de campanhas preventivas de SST no setor de transporte. Fragoso Jr. e Garcia (2019) mostram que a atuação da fiscalização do trabalho, por parte do governo, tem sido negativamente desproporcional à acidentalidade nesse setor, o que nos mostra que por algum motivo o setor de transporte tem sido relegado no que concerne à SST no Brasil. Caberia uma análise para saber se há algo intrínseco à atividade ou às relações de trabalho no setor, ou se se trata de algo mais específico da realidade brasileira. Ainda mais que, com a expansão dos serviços de entrega por aplicativos em meio a uma situação econômica de baixa oferta de empregos formais, o número de motofretistas e ciclofretistas tende a aumentar ou a se manter alto.

Para além das taxas e números de mortes no setor de transporte, em 2018, 74,8\% das greves no setor privado ocorreram no setor de serviços, sendo que o maior número de greves (35\%) do setor privado de serviços foi do setor de transportes (DIEESE, 2019). A greve dos caminhoneiros em 2018 foi a maior da história da categoria no Brasil, principalmente em termos de impacto na circulação de mercadorias e da produção no país. Foi também a greve de uma categoria de maior impacto na economia nas duas últimas décadas pelo menos. O seu impacto foi sentido também em ampliação da proteção trabalhista a essa categoria. Como aponta Filgueiras (2019), a conquista do valor mínimo de frete para os caminhoneiros supostamente autônomos levou a que o setor de transporte rodoviário de carga (CNAE 2.0) tenha tido o maior crescimento de emprego formal de 2018 a maio de 2019, com saldo positivo de 40 mil (por sua vez, os caminhoneiros considerados autônomos reduziram em 50 mil).

Embora na pauta de reivindicações dos caminhoneiros não houvesse menção explícita à saúde e segurança, indiretamente, como praticamente toda e qualquer reivindicação trabalhista que toca em aspectos da organização do trabalho, como a remuneração, ela acaba tendo relação com a saúde e segurança. Coincidentemente, como vimos, motorista de caminhão é a ocupação com maior taxa de mortalidade de acidentes típicos; e profissões de transporte rodoviários, como motorista de caminhão e motofretista, se destacam negativamente também em números absolutos de mortes por acidentes de trabalho típicos e aposentadorias por invalidez. O terciário, com a prestação de serviços e relação presencial com o público, e em específico as atividades de transporte tem trazido também mais uma preocupação relativa à segurança no trabalho, além dos acidentes. Trata-se da violência intencional, como em assaltos e latrocínios. Preocupação de caminhoneiros, taxistas e motoristas por plataformas digitais. Mesmo que não tenha relação direta com esse fato, a greve dos caminhoneiros de 2018 não deixa de ser simbólica do aumento da importância relativa, na economia e na sociedade, da mobilidade e da circulação. A gestão just-in-time é apenas um dos elementos que elevam a novo patamar a importância dos meios de transporte na economia e no próprio processo produtivo.

Vídeos públicos voltados ao setor rural na plataforma de acesso público que pesquisamos também são escassos, apesar das altas taxas de mortalidade e de aposentadoria por invalidez no setor. Uma hipótese, que talvez ajude a explicar em parte, é que possivelmente o veículo vídeo - principalmente os disponibilizados online - seja um 
meio de baixo alcance de mensagens preventivas no meio rural. Mas evidentemente podese aventar também que a invisibilidade dos trabalhadores desse setor, até mesmo por não estarem nos centros urbanos, também desempenhe um papel. Provavelmente também encontraríamos mais vídeos preventivos da saúde do trabalhador rural se tivéssemos utilizado termos de busca relacionados ao uso de agrotóxicos. Mesmo não sendo propriamente de prevenção em SST, campanhas contra o uso ou redução de agrotóxico acabam sendo indiretamente campanhas preventivas em SST, uma vez que visam reduzir ou eliminar um perigo e possivelmente um risco do processo produtivo. Mesmo o saber dominante em SST, que estabelece uma hierarquia preventiva começando pela eliminação da fonte de risco, parece não ser transversal a decisões de liberações de agrotóxicos pela Anvisa. Ao menos se considerarmos matérias da imprensa, nas quais a hierarquia de medidas de segurança parece não ser seguida nas decisões tomadas.

Professores, particularmente os da rede pública do ensino fundamental e de jovens e adultos, são uma categoria relativamente pouco representada na sua especificidade (para além de fatores de risco psicossociais gerais) através de vídeos de campanhas preventivas, apesar do alto número absoluto de afastamentos por doença ocupacional dessa categoria. Uma possível explicação seria o fato de servidores públicos não serem celetistas e, portanto, ficarem fora do âmbito jurídico de órgãos estatais que cuidam de relações de trabalho, como a Justiça do Trabalho, o Ministério Público do Trabalho e mesmo a Auditoria Fiscal do Trabalho (do antigo Ministério do Trabalho), o que se traduziria também no foco das campanhas preventivas desses órgãos se voltarem aos celetistas. De todo modo, mesmo entre os sindicatos de trabalhadores - sendo que aquele que é considerado o maior sindicato da América latina é o sindicato de professores do ensino público estadual de São Paulo - , e mesmo levando em conta que os sindicatos em geral produzem poucos vídeos de prevenção de SST, há relativamente pouca abordagem específica dessa categoria, que é grande e destacável pelos altos números de afastamento por doenças ocupacionais.

O número elevado de afastamentos por doenças ocupacionais de faxineiros, serventes de obra e vigilantes (DIEESE, 2016) também aponta a partir da seleção de vídeos analisados a baixa repercussão do adoecimento nessas ocupações em termos produção de materiais de campanhas preventivas públicas, ao menos em vídeo.

Apesar da predominância da população ocupada e dos empregos formais no setor de serviços, e de cerca de $80 \%$ das aposentadorias por invalidez decorrentes de doenças ocupacionais serem desse setor, os vídeos de campanhas preventivas em SST tendem ainda a focar, com exceção dos vídeos produzidos por sindicatos de trabalhadores, o setor industrial e de construção civil. A quantidade de afastamentos por acidentes, a gravidade e taxa de mortalidade desses dois setores justificam o enfoque neles. Porém resta a dúvida de que não desempenharia também papel nessa prevalência o fato do próprio campo de SST e de suas instituições como as conhecemos hoje terem se desenvolvido a partir dos conflitos industriais (FALEIROS, 1992), o que, portanto, os tornam mais propensos a abordar as atividades industriais e suas fontes de risco. 
Já nos vídeos das entidades sindicais predomina a abordagem do setor de serviços. $\mathrm{O}$ corpus não é uma amostragem estatística, mas na seleção dos vídeos para construir o corpus notamos essa tendência no universo de vídeos que nos deparamos na plataforma online utilizada. Procuramos assim selecionar os vídeos para compor o corpus de modo que ele refletisse essa tendência percebida no universo que nos deparamos. A estratégia de ocultação, como apresentada por Filgueiras (2017b), pode ser uma hipótese para explicar, pelo menos parcialmente, essas tendências dos vídeos empresariais e sindicais.

A hipótese seria de que as entidades empresariais tenderiam a fazer campanhas preventivas em SST quando a ocultação não é possível ou é difícil, e quando a estratégia de individualização também não é fácil. Na indústria e na construção civil, muitas doenças ocupacionais são de mais difícil ocultação, uma vez que costumam estar associadas a agentes químicos ou físicos aos quais os trabalhadores são expostos na sua atividade. Já as Doenças osteomusculares relacionadas ao trabalho (DORT) e patologias mentais, conjunto mais frequente no terciário, costumam ser ainda mais facilmente negadas/ocultadas como estando relacionadas ao trabalho. Se essa ocultação é mais fácil nas doenças predominantes no terciário, no entanto a individualização, isto é, a atribuição de culpa ou responsabilidade ao trabalhador, é mais difícil. Dessa perspectiva surge então a hipótese de que as campanhas preventivas de entidades patronais tendem a abordar acidentes, a indústria e a construção civil ao menos em parte pela ocultação não se mostrar eficaz nesses casos. Por outro lado, as entidades sindicais dos trabalhadores, focando no terciário e nas doenças, fariam o esforço oposto: de publicizar e desocultar esses adoecimentos como relacionados ao trabalho. Essa hipótese de explicação dos resultados da análise de conteúdo, a partir da estratégia de ocultação, no entanto se enfraquece na medida em que ela sozinha não é capaz de explicar a tendência dos vídeos produzidos pelas entidades estatais, que possuem tendência similar a dos vídeos empresariais no que diz respeito ao foco no setor industrial e de construção civil. Ou seja, apenas a estratégia de ocultação não explicaria a preponderância da indústria e construção civil nos vídeos empresariais.

\section{Proposições}

Para concluir, indicaremos algumas sugestões para campanhas preventivas em SST, tendo em conta o conhecimento estabelecido na área e os resultados desta pesquisa quanto aos setores, atividades e atores focalizados nas mensagens.

Primeiramente, em relação a comunicações corporativas, é preciso sempre lembrar que, caso a aplicação das medidas preventivas seja contraditória com outras exigências, como a de metas de produção, mensagens preventivas dirigidas aos atores de uma empresa podem acabar contribuindo para que muitos desses atores achem que a prevenção não é tão importante. Elas tendem a ser levadas a sério apenas se a empresa implementar várias medidas coerentes com as mensagens que se referem à importância das medidas de prevenção (DANIELLOU; SIMARD; BOISSIÈRES, 2010). Tendo isso claro, 
destacamos a seguir algumas proposições para audiovisuais de campanhas preventivas em SST:

a) Os vídeos de campanhas preventivas analisados apontaram que predominantemente as mensagens são dirigidas aos trabalhadores. Uma vez que acidentes e agravos são largamente compreendidos como consequências de decisões de diversos atores na sociedade e nas empresas, campanhas preventivas tendem a ser mais consequentes se não se fixarem no trabalhador como destinatário da mensagem, como já indicou Menéndez-Navarro (2019);

b) As ocupações e atividades de transporte rodoviário, como motorista de caminhão e motofretista, têm sido pouco abordadas, ainda mais levando em conta que se destacam em taxa de mortalidade, números absolutos de mortes e aposentadorias por invalidez. Sendo assim, são ocupações que merecem maior atenção preventiva, principalmente numa abordagem que trate de aspectos da organização do trabalho, saindo do foco comportamental (apelo à "atenção" e cumprimento de normas), trazendo aspectos de jornada de trabalho, formas de remuneração, controles etc. Aspectos esses que, evidentemente, variam tanto entre motoristas de caminhão e motofretistas quanto internamente em cada uma dessas ocupações, devido principalmente às diferentes relações contratuais existentes. Isso significa também que 0 condutor profissional - ou o "amador produtivo" no caso dos condutores por aplicativos (ABíLIO, 2017) - tem uma especificidade óbvia em relação aos condutores eventuais e amadores em geral, e portanto devem ser objeto de uma abordagem específica, fora de um tratamento geral de prevenção a acidentes de trânsito;

c) Os professores, como categoria que formam o maior sindicato da América Latina em número de filiados, e com os altos números absolutos de afastamentos por doenças ocupacionais, merecem atenção através campanhas preventivas, algo que praticamente não identificamos nos critérios de seleção desta pesquisa. Isso poderia ser levado adiante ao menos pelos próprios sindicatos da categoria, os quais poderiam abordar, a partir do conhecimento estabelecido, os determinantes organizacionais, políticos e sociais dessa alta incidência de agravos;

d) Algumas profissões como faxineiro, servente de obra e vigilante possuem altos números absolutos de afastamento por doenças ocupacionais, no entanto parecem ter pouca visibilidade, possivelmente advinda do baixo status social dessas profissões no Brasil, o que se refletiu na seleção de vídeos de campanhas preventivas realizadas nesta pesquisa. Abordar o adoecimento nessas profissões de baixa visibilidade social, mas de números elevados é algo a ser buscado;

e) Da mesma forma, abordar os trabalhadores informais e em relações contratuais diferentes do trabalho assalariado fordista parece se tornar uma 
necessidade ao campo da prevenção em SST que ainda se pauta pelo valor moral/humanitário, diante das mudanças advindas com a terciarização da econômica e a institucionalização de arranjos de relações de trabalho pósfordistas.

A pesquisa aqui apresentada se limitou à análise de campanhas preventivas de SST públicas, em vídeo. Embora seja perceptível que o formato audiovisual esteja em expansão com a ampliação dos potenciais da internet e dos smartphones, para uma visão mais completa e acurada dos conteúdos das campanhas preventivas no Brasil, e, portanto, dos setores e atividades mais focados ou preteridos e dos atores responsabilizados pela prevenção, se faz necessária a pesquisa de campanhas em outros formatos (textuais e imagens paradas, por exemplo).

Para além disso, um tema que se abre para atenção da sociedade e de pesquisadores são as implicações da ascensão de um clima político-social autoritário e da chamada altright ou nova direita, no mundo e no Brasil. Como aponta Waring (2019), em tal contexto emergente as questões de SST tendem a ser ignoradas e seus acúmulos e instituições confrontadas. A chamada reforma trabalhista - PL 6787/2016 tornado Lei em 2017 - é um exemplo (HOEFEL; PORDEUS; SEVERO, 2018). As repercussões desse contexto políticosocial nos agravos à saúde dos trabalhadores e no volume, difusão e conteúdo de campanhas preventivas em SST são, portanto, um campo a ser monitorado e pesquisado.

\section{Referências}

AARTS, Bas; BAUER, Martin. A construção do corpus: um princípio para a coleta de dados qualitativos. In: BAUER, Martin; GASKELL, George (org.). Pesquisa Qualitativa com Texto, Imagem e Som: um manual prático. Petrópolis: Vozes, 2008.

ABÍLIO, Ludmila Costhek. Uberização do trabalho: subsunção real da viração. Passa Palavra, 19 fev., 2017. Disponível em: <https://passapalavra.info/2017/02/110685/>. Acesso em: 18 out. 2019.

ALMEIDA, Ildeberto Muniz. Trajetória da análise de acidentes: o paradigma tradicional e os primórdios da ampliação da análise. Interface - Comunic., Saúde, Educ., v.10, n.19, p.185202, jan./jun. 2006.

DANIELLOU, François; SIMARD, Marcel; BOISSIÈRES, Ivan. Fatores Humanos e Organizacionais da Segurança Industrial: um estado da arte. Cadernos de Segurança Industrial, n.2013-07. Toulouse: ICSI, 2010.

DIEESE. Anuário da Saúde do Trabalhador. São Paulo: Dieese, 2016.

DIEESE. Balanço das greves de 2018. Estudos e Pesquisa, Rio de Janeiro, n. 89, abr. 2019. 
FALEIROS, Vicente de Paula. O Trabalho da Política: Saúde e Segurança dos Trabalhadores. São Paulo: Cortez, 1992.

FILGUEIRAS, Vitor Araújo. A Ocultação do Adoecimento Laboral no Brasil. In: FILGUEIRAS, Vitor Araújo. (org). Saúde e Segurança do Trabalho no Brasil. Brasília: Gráfica Movimento, 2017a.

FILGUEIRAS, Vitor Araújo. As promessas da Reforma Trabalhista: combate ao desemprego e redução da informalidade. In: FILGUEIRAS, Vitor Araújo.; KREIN, José Dari; OLIVEIRA, Roberto Veras de (orgs.). Reforma Trabalhista no Brasil: Promessas e Realidade. Campinas: Curt Nimuendajú, 2019.

FILGUEIRAS, Vitor Araújo. Individualização, saúde e segurança do trabalho no Brasil. In: FILGUEIRAS, Vitor Araújo. (org). Saúde e Segurança do Trabalho no Brasil. Brasília: Gráfica Movimento, 2017b.

FRAGOSO Jr. Ademar; GARCIA, Eduardo Garcia. Transporte rodoviário de carga: acidentes de trabalho fatais e fiscalização trabalhista. Rev. bras. saúde ocup., São Paulo, Fundacentro, vol. 44, 2019.

HOEFEL, Maria da Graça Luderitz; PORDEUS, Aléxia Rodrigues; SEVERO, Denise Osório. Reforma trabalhista no Brasil e a saúde do trabalhador: uma ponte para o século XIX. Tempus, actas de saúde colet, Brasília, 12(1), p. 59-71, dez, 2018.

LIBERATO, Leo Vinicius Maia. Viradas do Avesso: percepção dos trabalhadores, constituição e existência de ferramentas de SST. Revista Latinoamericana de Estudios del Trabajo, Rio de Janeiro, ALAST, v. 19, p. 39-64, 2014.

MENÉNDEZ-NAVARRO, Alfredo. A Arte de Prevenção em Segurança e Saúde no Trabalho. São Paulo: Fundacentro, 2019.

MINISTÉRIO DO TRABALHO. Relação Anual de Informações Sociais (RAIS) 2016. Análise dos Principais Resultados. Brasília: Ministério do Trabalho, 2017.

NICHOLS, Theo. Death and Injury at Work: A Sociological Approach. In: DAYKIN, Norman; DOYAL, Lesley (eds.). Health and Work: Critical Perspectives. New York: St. Martin, 1999.

VINICIUS, Leo. Antes de Junho: Rebeldia, Poder e Fazer da Juventude Autonomista. Florianópolis: Em Debate, 2014.

WARING, Alan. (2019). The five pillars of occupational safety $\&$ health in a context of authoritarian socio-political climates. Safety Science, 117, p. 152-163, 2019. 


\section{Informações sobre 0 autor:}

\section{Leo Vinicius Maia Liberato}

Doutor em Sociologia Política pela Universidade Federal de Santa Catarina (UFSC), com pós-doutorado em Filosofia pelo Departamento de Filosofia da Universidade de São Paulo (USP). Atualmente é Tecnologista Pleno II da Fundação Jorge Duprat Figueiredo de Segurança e Medicina do Trabalho (FUNDACENTRO).

ORCID iD: http://orcid.org/0000-0001-9407-7559

E-mail: leo.liberato@fundacentro.gov.br

Submetido em: 24/01/2020

Aprovado em: $20 / 04 / 2020$

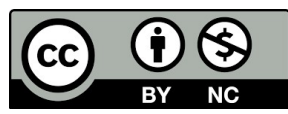

Esta obra está licenciada com uma Licença

Creative Commons Atribuição - Não Comercial 4.0 Internacional 